\title{
The Research of Speaking Process in Language Attention System*
}

\author{
Xianqing Liu \\ College of International Studies, Southwest University, Chongqing, China \\ Jinyan Fan \\ School of Foreign Languages and Literature, Chongqing Normal University, Chongqing, China
}

\begin{abstract}
Speaking process and language attention are hot topics in current psycholinguistics and cognitive linguistics separately. By the example of Levelt's Speaking: From Intention to Articulation, taking Talmy's theory of language attention system as a guide, this paper explores how attention is represented in speaking process.
\end{abstract}

Index Terms - attention, message, prominence, focus, topic

\section{INTRODUCTION}

Language attention is one of the hot topics in current cognitive linguistics. For the research of language attention, it is now from singleness to system, and the language attention system of Talmy (2007; forthcoming) is formed in this research background. The process of speaking is one of the focuses for both psychologists and psycholinguists and Levelt (2008) is the most excellent one. Although Talmy and Levelt have got remarkable achievements in their own research field, they are still limited on the following aspects. 1) Talmy's research is mainly involved the constitutive factors of language attention system, while for the interactive process that how the speaker by help of this system to produce expressions, and, how the listener, based on those expressions to allocate his attention to language is seldom concerned. 2) What Levelt cares for is how attention monitors the production of language in the cognitive psychological process of speaking, while the leading and the distribution of language on attention are hardly neglected. This paper, taking Levelt's process of speaking as the object of study and Talmy's attention system of language as the theoretical guide, explores how attention is represented in the process of speaking from the cognitive perspective.

\section{THE PROCESS OF SPEAKING}

In our study, the process of speaking refers to the psychological process that the speaker produces one utterance and the hearer understands it. From the perspective of the psychological relationship between attention and language, the process of speaking is involved at least the following two aspects.

\section{A. The Monitoring of Attention on Language Production}

The topic of the monitoring of attention on language production interests many psychologists. Mainly, there are three monitoring theories: the editor theory, the spreading activation theory and the perceptual loop theory. Among the three theories, the perceptual loop is the most popular, which argues that monitoring can have the speaker discover speech mistakes, and self-repairing is the explicit manifestation of it. Similarly, Ferreira \& Bailey (2004) thinks that, reparandum, suspension point, and edit term are typical non-fluent utterances.

For the cognitive process of speaking, Levelt (2008, p. 2-8) takes (1) as a case to explain how the speaker monitors and repairs his own utterance.

(1)...

Academic $_{1}$ : [e:m] ...would you say Othello was [e:]...a tragedy of circumstance... or a tragedy of character.

(lapse)

Student: I I don’t know the way...play WELL enough sir.

$\ldots$

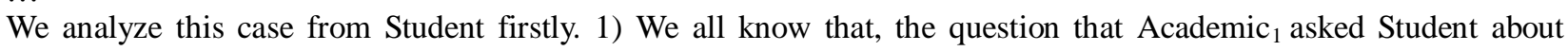
"Othello" is not because of Academic ${ }_{1}$ 's short knowing on the play himself; on the contrary, his aim is to know how much Student knows about the play. 2) Both Academic ${ }_{1}$ and Student know their own role in the dialogue. 3) There is a detail, which is the key to produce the above utterance. That is, Academic ${ }_{1}$ does not notice that his partner $\left(\right.$ academic $\left._{2}\right)$ asked Student an almost same question "Would you call Othello a tragedy of circumstance or of character?" five minutes ago and Student's reply "I don't know much about Othello, so I couldn't say." is to show that he is incapable of

\footnotetext{
* This research is financed by Chongqing Normal University No. 2011XWQ18.
} 
this question.

We secondly analyze this case from the psychological process which Student produces the utterance. He chooses"I"as the beginning. Because of his inward anxiousness, and the effective information he can not find, he has some waver so he utters two "I" continuously, then he keeps silence for a long time. Here "I" is the experiencer, and the choice of "I" strictly limits the speaker's following choice, that is, to choose a verb to realize the subject role of "I". The verb "know" represents the state of knowledge. If "don't" is ignored, "Othello" as the object of "know" can be seen as Student's state of knowledge about Shakespeare's plays.

Thirdly, we will analyze the situation in which the mistake "way" is produced. In order to activate the word "way", Student should be thinking its meaning, for instance, he may think "I don't know the way". If we are right, "way" should not appear in the surface structure of the utterance here. At the same time, "way" should not be the part of the meaning of the utterance expresses here. This can be inferred from the answer which Student gives to academic $c_{2}$. It is obvious that at least Student knows that the question that Academic $_{1}$ asked is related with plays (This is also inferred from his repair that "play" for "way" later, while he does not know so much about this question). So we are sure that this mistake is produced in the situation that Student is anxious and awkward, at the same time, it is because of the similarity of "way" and "play" on pronunciation. To some degree, it is homonymic with "play", but not because of the blending of "WELL" and "play" in spelling.

Now the question is why Student can discover and repair his mistake by himself without any cue from Academic $_{1}$, Academic $_{2}$ and the context.

In fact, for Student, noticing the mistake of "way" is not sudden. It is because his attention performs a monitoring function for the utterance of the speaker in the cognitive and psychological process of speaking. After the speaking of "way", Student pays attention to the inconformity of meanings between the word and the meaning what he wants to express immediately. So after the short halt, he quickly repairs his mistake by "play.

According to Kormos (2006) and Caroll (2008), all the theories of the process of the language output are same in the following points: 1) The output of language includes four stages - the concept formation, the constitution, the pronunciation and the self-monitoring. 2) The operation of the four stages obeys the order of the arrangement here. 3) The basic working mechanisms of language output are activation and spreading.

Levelt (2008) thinks that the blueprint of the speaker and the cognitive process are formed by the following components: (a) Conceptualizer, (b) Formulator, (c) Articulator. The concrete operation of this model can be summarized as that the Conceptualizer produces the preverbal message, the preverbal message is put into the Formulator, the Formulator produces the internal phonetic plan, the internal phonetic plan is put into the Articulator and the Articulator produces the language which we can hear. On the other, the speaker can monitor his utterance by his speech comprehension and audition system, and then he may discover, repair and correct his utterances.

\section{B. The Leading and Distribution of Language on Attention}

The study of language and attention is mainly focused on psychology, psycholinguistics and cognitive linguistics. Psychologists mainly construct the related theoretical frames around attention. What the psycholinguists care for is the monitoring function of attention on the process of speaking. While for the cognitive linguists, what interests them is the language's leading and distribution for language user's attention.

Talmy (2007; forthcoming) argues that there is a wide attention system in language, and it is because of this attention system which distributes different attention to the different parts of language expressions. For the speaker or the hearer, consciously or unconsciously, the quite a few factors in language can influence the language user's attention distribution. And these factors can have the language user increase or decrease his attention on one or more aspects of language expressions.

Carroll (2008) claims that the prosodic factors of language include accent, intonation and frequency. As a matter of fact, the prosodic factors still include halt, tone, tune-pattern and gestures and so on. Talmy (forthcoming) thinks that, speech sound as one of the important factors constructing the attention system of language is mainly presented on the strength and the length of speech sound. For instance, when the accent is on one morpheme or word, the speech sound of that morpheme or word will be strengthened and at the same time, the attention of distribution of that morpheme or word will be increased. The longer of the speech sound of a morpheme or a word, the attention of distribution of that morpheme or word will be increased also.

(2) My son is also going to PARIS.

(3) They promised they would phone me. Nevertheless/But they never called back.

In (2), the accent is on "PARIS", so it gets more attention. In (3), the meanings of "Nevertheless" and "but" are almost same, but because the sound of "Nevertheless" is longer than "but", so it gets more attention distribution.

Talmy's argument that language can influence language user's attention leading and distribution is perfectly used by the speaker and the hearer in Levelt's language process of speaking.

From the perspective of the speaker, why Student produces the utterance of (1), that is "I don't know the way...play WELL enough sir" is because: 1) Academic $_{1}$ does not notice that his partner once asked Student a similar question, and

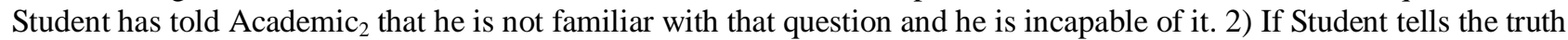

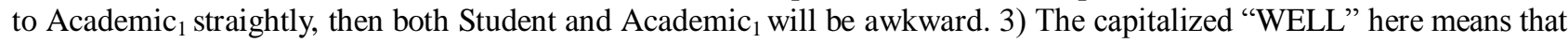
in his answer, the student adopts an accent on it. Then, what is the purpose of this accent? Simply speaking, Student 
does not express his meaning directly, but adopts accent, one factor of language attention system to adjust the attention distribution of Academic ${ }_{1}$, that is to say, the speaker has the one which should not be accented originally accented, his purpose is to have the hearer distribute more attention on that word.

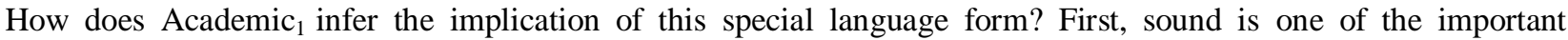
constructing factors of language attention system, which can influence the hearer's attention distribution. Second, what the speaker gives an accent to "WELL", which should not be accented originally is the speaker's unconscious use of the sound factor of language attention system. Finally, the hearer can also make use of the language attention system in order to realize the leading and the distribution of language on attention.

In the case of (1), the hearer, that is Academic $_{1}$ will get a full of surprise, because he can, of course notice that "WELL" is accented, which should not be in normal situation. Then, we are sure that the hearer will focus his attention on "WELL" quickly. According to Langacker's (2012) "moving window of attention" theory, here "WELL" is regarded as rhythmic focus appearing in the current attention window and it gets focus attention distribution. In the end, after a quick thinking, from the present situation, Academic 1 will infer the implied meaning of "WELL", then corrects his own mistake.

In the following section, we will discuss the language leading and distribution on attention from the aspects of the generation of message, the show of the salience, the production of focus and the choice of topic.

1. The generation of message

Levelt (2008) holds that the communicative intention is the mother of speech act and he argues that the biggest communicative intention of speaker is to have the hearer understand his intention. In the process of communication, the aim of communication can be shown by various means, and each mean needs the speaker to find new expression. This process involves the thinking of the communicative intention, the choice of related expression, and the arrangement of the order of the related information, expression and the other complex factors. Kecskes (2010) points out that, the verbal communication is not fluent like the description of the current theories of pragmatics. When he talks the status of the speaker and the hearer in the process of speaking, Kecskes (ibid) argues that the speaker and the hearer act as different individual but the same important communicators appear in the process of communication. Kecskes (ibid) thinks that what the two aspects of a speaker to generate an utterance and a hearer to understand an utterance depend on is the most accessible and prominent knowledge in the former context.

According to Levelt (2008), the first step of the production of speech is the generation of preverbal message and he thinks that preverbal message is the primary stage of communicative intention. The fact here is obvious that by his speaking, the speaker has the hearer see his intention. Since the communicative intention exists here, the speaker will choose the expressions which include the communicative purpose. Then it is concerned the choice of words, sentences and utterance rhythm. We know that these choices certainly need the speaker's attention resource, and at the same time, we know that a speaker's attention is limited, so in definite time he can only have limited attention to notice some parts of a certain language, so in utterance expression system, only one or a few parts is in a higher activation.

The concrete generation of message in the process of speaking is formed by macroplanning and microplanning. The former divides the communicative intention into a series of targets and sub-targets and it also chooses proper information for each sub-target and the result of output is speech act. On the microplanning, the speech act should also take into consideration of perspective, the format of proposition, the design of information structure, including topic, focus, and the distribution of new information. In order to satisfy the requirement of message, the speaker must master some special language skills so that the communicative intention can be realized at utmost. The information choice of macroplanning needs quite a lot of plans, memories, searches, inference, and all the activities need the speaker's attention resource. Similarly, microplanning also need the speaker's attention resource.

As a matter of fact, in the psychological process of Levelt's speaking, for the generation of message, including all the ways of the message producing, all the language mechanisms of having utterances into activation, they are all related with prominent mechanisms of expressions, and all the prominent mechanisms are interlinked with all the constructing factors of language attention system of Talmy, so to most of degree, Levelt and Talmy's researches have great similarity in cognition.

For example, from the perspective of semantics, the semantic component of a message is not with or without, but it is a degree of activation or prominence. The prominence in Formulator is realized by all kinds of lemmas, the details of modifiers and ways of word order. At the same time, the thematic related concept of a message will be different because of its importance, prominence and centrality. So, in the process of speaking, the speaker will place some relation on foreground, and the other on background. For example:

(4) Mary received the book from Tina.

(5) Tina gave the book to Mary.

According to Talmy's attention system of language, "Mary" in (4) will get more attention distribution than "Tina". "Tina" in (5), on the contrary will get more attention distribution than "Mary". So, in a language situation, the speaker not only chooses the role of expression, but also decides which role in the foreground, and, which one in the background. The component of foreground is usually called nuclear (Nooteboom \& Terken, 1982). The nuclear component usually bears the main grammatical function, while the non-nuclear, the sub-grammatical function.

In a word, in the process of the generation of message, the choice of roles, the decision of foreground or background 
and the giving of main grammatical function and sub-grammatical function, they are the fact that the speaker and the hearer consciously make use of the attention system of language to realize the different attention distribution on language components.

2. The show of the salience

Levelt (2008) argues that, in the process of speaking, when the speaker introduces the new entity into discourse, for the hearer, the new entity has new value, and then, it gets prominence on concept. Of course, the entity which has existed in discourse may also have new value if it gets prominence.

Suppose there is a dialogue between Tom and Mary. In the dialogue, what they first talk is three boys (Jack, John and Williams), now then change to the argument that the three boys argue with a girl (Alice), after introduction the main character "Alice", Tom may speak (6).

(6) Alice pestered JAck, then she insulted JOhn, and finally she hit WILliams.

In (6), "Jack", "John" and "WILliams" are there in the discourse, but they still get pitch accent separately. After their experiment, Nooteboom \& Terken (1982) point out that, for the hearer, the same thematic role may get different reference. In (6), why "Jack", "John" and "WILliams" get pitch accent separately is because they are the victims of "Alice" and that is the one which this sentence emphasizes. In order to mark this new referential meaning, the speaker has it be prominent by pitch accent and by this way, he can have the hearer give more attention distribution on it. If the thematic role is same, and the reference does not change, the speaker will not have it be prominent. In (6), "Alice" is used as the agent of the action, and it is not accented in the second or third time, no matter its first beginning is accented or not. So we can say that as anaphoric way, a pronoun should not get pitch accent, but we should notice that if the reference of a pronoun has some change, the anaphoric pronoun can also be prominent and be accented.

(7) Alice went after Jack, and then hE chased hER.

In (7), "Alice" and "Jack" are replaced by "he" and "her" separately, but they still get pitch accent. This happens because their references are changed, so they should be distributed more attention.

In the process of speaking, the prominent component of a message does not only refer to the referent item, but also a predicative component if it has new value. Besides the phonation, there are some other prominent ways, including not only morphology, syntax, context, discourse, but also the cultural differences. The cognitive linguists call these prominent means as figure and ground, profile and base, trajector and landmark and foreground and background. In the process of speaking, both the speaker and the hearer will make use of these cognitive mechanisms of language consciously to realize the different prominence to the different parts of utterances, which can have the utterances get different attention distribution.

3. The production of focus

The phenomenon of focus is involved phonology, syntax, semantics, and pragmatics and so on. So, we can say the study of focus is the ideal experimental field among the interface of phonology, syntax, information structure, semantics and pragmatics. On the one hand, it is concerned the interaction among the factors of phonology, syntax, semantics and pragmatics and so on. On the other, it can also help us to know their functions of all the factors in the complex interactive process.

From the process of speaking, because the speaker's attention scope is very limited, so in the plan of the output of one utterance, the speaker can only design one or a few concepts. This is the same to the hearer. Jackendoff (1972) thinks that the focus of a sentence is the one in which the speaker supposes that is the formation which he can not share with the hearer. The example is in (8).

(8) "What does Tom write?"

Based on the of focus, Grosz, Joshi \& Weinstein (1995) study further and advocate focus center. They think that focus center refers to the focus which the speaker establishes in present discourse and they also think that a speaker's focus center may not be the same as the hearer.

In the process of speaking, Levelt (2008) also proposes a concept of new focus. In Levelt's study, the new focus refers to the part of a discourse that the hearer is caring for now but not in the past. For example, in (9), "JOHN" is the new focus, which is also called by Levelt as prosodic focus. Compared with "Mary", the hearer may distribute more attention to "JOHN".

(9) Tom saw much of Mary recently. But yesterday he visited JOHN."

According to Talmy's (forthcoming) theory, the attention system of language itself distributes different attention to the different part of language, in which some factors of the attention system will increase the attention distribution to language expressions, while the others may decrease the attention distribution. So, in the process of speaking, the focus information should get most distribution of attention by the usages of some mechanisms in language attention system. On the one hand, most of the means of the focusing realization are the important factors of Talmy's language attention system. On the other hand, the means of the focusing or the mechanisms which lead to different attention distribution interest quite a few scholars. For example, Langacker (2008) thinks that the semantic functions of the subject and the object in a same sentence are different. The semantic polar, which bares the subjective function is called as Trajactor (TR), while the one which bares the objective function is called as Landmark (LM). According to Langacker (ibid), the semantic relation between TR and LM is not equal. Generally speaking, TR refers to the focus or the more prominent one, while LM refers more to the background participant. So in the normal word order of a sentence, TR (subject) 
appears first, while LM (object) later.

(10) John ate all the chocolate.

(11) All the chocolate was eaten by John.

In (10), "John" is the focus participant (TR), the agent, while "chocolate" is the second participant (LM), the patient. In the traditional grammar, (11) is the passive form of (10) and the semantic value of (11) and (10) is equivalent. While the cognitive linguist, on the contrary, does not agree. According to the cognitive linguist, there are obvious differences of the semantic value between (11) and (10). In (11), "all the chocolate" is figure, while in (10), it is ground. That is to say, the nonfocus of "all the chocolate" in (10) is realized as semantic focus in (11). From the perspective of attention system of language, "all the chocolate" in (11) will get more attention distribution than it in (10).

4. The choice of topic

As a special foregrounded component, "topic" is always an important and hot issue in the study of linguistics. Hockett (1958) advocates the terms "topic" and "comment" firstly. He thinks that topic is the beginning of information, while comment is the purpose of an utterance. Until today, the scholar can not get an agreement on the definition of topic. Some of them regard it as a grammatical concept, while the others take it as a pragmatic concept. Some of them say that topic is formed by sentence topic and structure topic, while for the other, it is about utterance topic or discourse topic.

Pedersen (2011) and Krifka (2007) think that, the unsymmetrical double parallel and the laterality evolution of human head can find the cognitive motivation in topic-comment and foreground-background. When a speaker chooses certain of information to express his communicative intention, he will make best use of ways to absorb the attention of the hearer. Among those various ways, to choose a referential entity as topic is an important one.

(12) Judie is married to Peter.

If the speaker's intention is to tell the hearer about "Judie", he may choose (12) to express. In (12), "Judie" is topic. The hearer will store the new information (being married to Peter) to the address of "Judie" in the discourse model. If there is an accessible address for "Peter" in the discourse or out of the discourse, the hearer will store the information of "Peter" to the address of "Peter". When the speaker takes "Judie" as topic, his intention is only to store the new information under the address of "Judie. He may hope that the hearer concentrates his attention on "Judie" but not "Peter". For this process, Levelt (2008) shows us the following procedure to explain.

(13) IF the goal is that the hearer store the information under address X, THEN assign topic status to X.

We here can interpret the design of (13) from the following two aspects. Firstly, because of the explicit question of the dialogists, such as in (12), it is "Is your sister married?" Second, what is the reason of the prominence of the communicative event? In the process of the choice of topic, generally speaking, if the agent is a man, it is much easier to be used as topic than the nonhuman theme. The bigger and moving objects are easier to be topicalized than the smaller and stative objects. In the speaking process, the prominent items are usually be topicalized and placed at the beginning of an utterance by the speaker in order that the hearer can understand that this utterance is around this topic at the very beginning, and then, the hearer may distribute more attention to it. What here we should point out specifically is that, when these prominent items are introduced into the discourse, the speaker does not give them prominent marks. On the contrary, the rheme which is used to state the topic, that is, the items containing new information can be prominent.

(14) I have a sIster. She is mArrid.

In the first part of (14), it brings a new reference to the hearer's focus attention. Because this reference is not accessible for the hearer in the former discourse, the speaker uses the complete "sIster", and at the same time, he gives "sIster" a rhythmic prominence. By this way, the hearer establishes a new address in the discourse for the new reference. In the second part of (14), the reference is now the topic and it exists there in the speaker's current focus, so the speaker adopts its short form "She" not the complete one, and at the same time, it does not have the rhythmic prominence. On the contrary, the theme "mArrid" gets prominence, because it is the new information now.

Hockett (1958) argues that in English or the familiar European language, generally speaking, a topic is the subject of a sentence, while the comment is as object. So he claims that the sentence topic is consistent with the grammatical subject of a sentence. Givón (1979) also claims that in the developing process of grammar, the subject of a sentence is derivate from grammaticalized topic. After a reference in the message of a speaker is topcalized, it will have advantages in the grammatical encode. In the normal situation, a speaker will place the topic of a sentence on the place of the grammatical subject or at the beginning, that is to say, to settle it on the topic place.

Being similar with the choice of the topic in the process of speaking, in the attention system of language, Talmy (forthcoming) thinks that, for a language expression, the different grammatical role it bears, the different place it occupies, it will get different attention distribution. The grammatical role and word order are also the important constructive factors of language attention system. Generally speaking, for a word, if it is at the beginning, as the topic and the subject, it will be prominent than the language expression in the place of object, and for the object, the direct object is more prominent the oblique. Talmy (forthcoming) argues that it follows this order: subject>direct object>oblique.

(15) The landlord rented the apartment to the tenant.

(16) The tenant rented the apartment from the landlord. 
Both "The landlord" in (15) and "The tenant" in (16) are in the place of topics, coincidence with e the subjects. Both "The landlord" in (15) and "The tenant" in (16) appear as figure, so the attention they are distributed in their own sentence is more than "the apartment", which is in the place of comment, being used as object and ground.

\section{CONCLUSION}

The conclusion of this study is as follows: 1) What psycholinguists care is the monitoring function of attention in speech production, while what cognitive linguists care is the language's leading and distribution for attention. 2) In the process of speaking, these two aspects are not independent completely; the former is the basis of the later. 3) In the complex psychological process of speaking, the cognitive linguist provides motivation proof for the achievement of the psycholinguist from the language perspective, which proves once more the cognitive linguist's claim that there is a similarity between the cognitive mechanisms of man's language and the others. 4) The theoretical achievements of both psycholinguistics and cognitive linguistics can draw lessons from each other and develop together.

\section{REFERENCES}

[1] Carroll, D. W. (2008). Psychology of Language. Beijing: Foreign Language Teaching and Research.

[2] Ferreira, F. \& K. Bailey. (2004). Disfluencies and Human Language Comprehension. Trends in Cognitive Science, 8, $231-237$.

[3] GivÓn, T. (1979). On Understanding Grammar. New York: Academic Press.

[4] Grosz, B., J, A. Joshi \& S. Weinstein. (1995). Centering: A Framework for Modeling the Local Coherence of Discourse. Computational Linguistics, 2, 203-225.

[5] Hockett, C. F. (1958). A Course in Modern Linguistics. New York: Macmillan.

[6] Jackendoff, R. (1972). Semantic Interpretation in Generative Grammar. Cambridge: MIT Press.

[7] Kecskes, I. (2010). Socio-cognitive Approach to Pragmatics. Journal of Foreign Languages, 5, 2-20.

[8] Kormos, J. (2006). Speech Production and Second Language Acquisition. New Jersey: Lawrence Erlbaum Associates.

[9] Krifka, M. (2007). Functional Similarities between Bimanual Coordination and Topic/Comment Structure. Interdisciplinary Studies in Information Structure, 6, 13-55.

[10] Langacker R W. (2012). Access, Activation, and Overlap: Focusing on the Differential. Journal of Foreign Languages, 1, 2-24.

[11] Langacker, R. W. (2008). Cognitive Grammar: A Basic Introduction. Oxford: Oxford University Press.

[12] Levelt, W. J. M. (2008). Speaking: From Intention to Articulation. Cambridge, MA: MIT Press.

[13] Nooteboom, S. \& J. M. B. Terken. (1982). What Makes the Speaker Omit Pitch Accents? An Experiment. Phonetica, 39, 317-336.

[14] Pedersen, E. E. (2011). Cognitive Foundations of Topic-comment and Foreground-background Structure: Evidence from Sign Languages, Cospeech Gesture and Homesign. Cognitve Linguistics, 4, 691-718.

[15] Talmy, L. (2007). Attention phenomena. In D. Geeraerts \& H. Cuyckens (eds.), The Oxford Handbook of Cognitive Linguistics. Oxford: Oxford University Press264-293.

[16] Talmy, L. (Forthcoming). The Attention System of Language. Cambridge: MIT Press.

Xianqing Liu was born in Chongqing, China in 1976. He received his M. A. in College of International Studies, Southwest University, Chongqing, China.

$\mathrm{He}$ is currently a lecturer in the School of Foreign Languages \& Literature, Chongqing Normal University and a Ph. D candidate of Southwest University, Chongqing, China.

His research interests include cognitive linguistics and second language acquisition.

Jinyan Fan was born in Sichuan, China in 1979. She received her M. A. in College of International Studies, Southwest University, Chongqing, China.

She is currently a lecturer in the School of Foreign Languages \& Literature, Chongqing Normal University, Chongqing, China.

Her research interests include cognitive linguistics and second language acquisition. 